Chairman GrodT. If there is no further discussion, we will proceed to the next topic, "Importance of Full and Accurate Descriptions of Varietal Differences in Growing Seed of Market Vegetables,"; by Mr. W. W. Tracy, of the United States Department of Agriculture.

\title{
IMPORTANCE OF FULL AND ACCURATE DESCRIPTIONS OF VARIETAL DIFFERENCES IN GROWING SEED OF MARKET VEGETABLES.
}

By W. W. Tracy, U. S. Department of Agriculture, Washington, D. C.

What I have to say refers to breeding and growing seed for use in producing market crops rather than to breeding for the production of new varieties, or even to the improvement, in the sense of modification, of old ones. Under modern methods of growing and marketing vegetables, uniformity, both of growth and of product, is a great desideratum, and variations in individual plants, even if it comes from the greater development of an intrinsically desirable quality, is a disadvantage. This can be made clearer by an illustration.

The profit or loss on a crop of green peas is often determined by a difference of a few days in the time when the pods reach a marketable size. In our best stocks of market sorts, all the plants mature their pods so nearly together that under the most favorable conditions the greater part of the crop can be gathered in a single picking; and it should never require more than three pickings all made within ten to fourteen days to secure practically all of it. Now if to a stock of peas, in which practically all the pods mature to marketable size in 50 to 55 days, we add 10 per cent of one which matures pods in 45 , we have materially hastened the average date of maturity and so seemingly increased its value; but in reality we have materially reduced it for it is impracticable to make a special picking of this 10 per cent of early pods. To do so would so injure the vines as to reduce the total yield by much more than 10 per cent besides requiring the extra time in picking, while if these early maturing pods are left on the vines and gathered with the bulk of the crop, they become so mature as to lower the grade and value of the whole crop. So that in practice, while the use of a stock, all or nearly all of which was five days earlier, might more than double the receipts, the use of one, only 10 per cent of which was five days earlier, would materially lessen them. The same conditions hold with reference to other qualities. The uniformity of product is often as important a factor in determining the practical value of a lot of seed as is any other quality. The exhibitor may aim at the production of superlative individuals regardless of the general average; the market man must depend upon uniformly good quality and to him superlative individuals are often as objectionable as those which are markedly inferior.

The perfection of development of a plant is perhaps most largely 
determined by its environment; but its character, the potentiality and limitation of development are inherent in the seed and are made up of the balanced sum of influences it inherits in varying degrees from each of its ancestors for an indefinite number of generations back. Under the best modern cultural conditions, the environment of different plants in a field is practically the same, but there is usually a great variation in the quantity and quality of the product, much, if not most of which variation is due to differences between individual seeds. There are few crops where the profit would not be greatly increased, and it could often be doubled, if the product of each one of the individual plants in the field were just equal in quantity and quality to that of the second best one-third of them.

I believe that improvement in this respect can come only through an appreciation on the part of seed growers of the importance of seed breeding and growing, of rigid adherence from year to year to precisely the same varietal types and such adherence can only be possible when such varietal types have been very clearly defined and described.

Do we have in the case of garden vegetables clear definite and explicit descriptions of just what any particular variety should be? I think not. In the case of plants propagated asexually, exact definitions of varietal characteristics is not so important. Since we cannot change it, we can only increase the number of parts of a certain definite thing-we cannot alter its inherent character. The Baldwin apple of to-day, of 50 years hence, is precisely the same in its character, its potentialities and limitations of development as that of 50 years agu. No matter how many propagative generations it may go through, the type of the variety as a variety cannot change; yet such men as Downing, Warder, and Beach have devoted years of earnest study, not only to the adaptability of the sort to certain places and uses, but to formulating clear descriptions of just what it is. On the other hand, in vegetables where the permanence of a variety and the retention of its qualities depends upon a clear statement of its distinguishing characteristics very litte work has been done, and it is not surprising that the slate-colored, nearly smooth-skinned Hubbard squash of 50 years ago drifts into the densely warted, dark-green Hubbard of to-day, which many claim is as unlike the original type in quality of flesh as it is in character of the skin, and no man can do more than guess what the Hubbard squash of 50 years hence may be. What the original introducer now selects as an ideal and typical ear of Premo corn is very different from one he picked out as an ideal five years ago when it was first named as a distinct variety. When we remember that the relative influence of each ancestor may vary in each individual and the great variation represented in the ancestry of the different plants of most stocks of garden vegetables, it is not surprising that they are variable, nor that some individuals are very different and of immensely greater practical usefulness than are others though they fail to transmit that superiority to their descendants. The only way we can secure seed certain to develop plants of an exact type is to make sure that each and all of its ancestors are of that exact type; and to do this, 
we must have the type clearly defined and, in selection, adhere rigidly to it and not be tempted into the use of plants that vary from the type even though they be individually superior. The first requisite for this is the formation and general acceptance of minute and exact descriptions of varietal types. This is by no means an easy task. We must first distinguish between what are real varietal and hereditary characteristics, and those which are simply the result of environment of the individual, for it must be admitted that conditions of environment sometimes induce modifications in the character of the plant, and when the same conditions are continued from year to year they have a cumulative influence, the effects of which may become hereditary; but such variations are less common and generally far less important than characteristics which are inherent in the nature and habit of the plant itself and quite independent of environment. Again, the comparative and practical importance of variations should be considered. Often there are correlations of qualities through which a readily seen variation, which is of jtself of little moment, becomes very important because it is very distinctly characteristic of the sort or is invariably correlated with some important quality which cannot readily be seen.

Again, the relative importance of certain qualities will vary with the conditions under which the plant is to be grown and the uses to which it is to be put. I have known of a number of instances when the very qualities which made a sort desirable for certain places and uses, and the development of which was the only reason for its existenc as a distinct variety, have been bred out of it; because, under the conditions and for the purposes with which the seed grower was familiar, these qualities were objectionable rather than desirable. These conditions make it seem to me that the formation of full, minute, and carefully written out descriptions of what the ideal plant of a variety shall be, and the rigid adherence in selection to that exact type from year to year, is the essential foundation for all really successful seed growing. And that there is to-day no greater horticultural need than the formation of such full and accurate varietal descriptions of vegetables as we now have of fruits.

\section{THE INHERITANCE OF SIZE OF IITTER IN POLAND CHINA sows.}

By Geo. M. Rommer, Animal Husbandman, U. S. Department of Agriculture, Washington, $D$. $C$.

Has the size of litter of Poland Chinas decreased? One of the most interesting studies on which the writer has been recently engaged is that of the size of litter of our American breeds of hogs and the inheritance of this characteristic from mother to daughter, especially as regards the Poland China breed. 